\title{
Location-Based Games and the COVID-19 Pandemic: An Analysis of Responses from Game Developers and Players
}

\author{
Samuli Laato ${ }^{1}\left(\mathbb{D}\right.$, Teemu H. Laine ${ }^{2, *}$ and A.K.M. Najmul Islam ${ }^{1}[$ \\ 1 Department of Future Technologies, University of Turku, 20540 Turku, Finland; sadala@utu.fi (S.L.); \\ najmul.islam@utu.fi (A.K.M.N.I.) \\ 2 Department of Computer Science, Electrical and Space Engineering, Luleå University of Technology, \\ 93187 Skellefteå, Sweden \\ * Correspondence: teemu@ubilife.net
}

Received: 6 April 2020; Accepted: 12 June 2020; Published: 17 June 2020

\begin{abstract}
In early 2020, as a countermeasure to mitigate the spread of the COVID-19 pandemic, governments issued limitations on the movements of their citizens, cancelling social events and advising people to stay home. As location-based games (LBGs) have been found to influence human movement, their role during COVID-19 deserves closer inspection. Under regular circumstances, the very aim of these games is to motivate people to go out, explore and meet other people. However, during COVID-19, people were advised to do the exact opposite. To study how LBG developers and players reacted to the situation, we used the netnography research method utilizing three types of data: (1) COVID-19 related in-game changes made by seven popular LBG developers during March 2020; (2) social media reactions on 20 posts across three popular Pokémon GO subreddits; and (3) the raiding activity (collaborative play) in Pokémon GO in a Finnish municipality during February-May 2020. All observed LBGs made in-game changes due to COVID-19. The social media reactions showed overwhelming appreciation towards these changes, and two central second order themes arose: (1) LBGs have the ability to influence human movement during pandemics; and (2) people should be able to self-regulate their behaviour during COVID-19 independent of LBG influence. Surprisingly, recorded Pokémon GO player activity in Finland was more influenced by offered in-game rewards than the COVID-19 pandemic. Our findings have implications on how games and gamification can be used to direct human movement in situations such as COVID-19 where population-level interventions are needed.
\end{abstract}

Keywords: COVID-19; Pokémon GO; behaviour; pandemic; location-based games; hybrid-reality games; social media; gamification

\section{Introduction}

Location-based games (LBGs) are multimodal mobile applications that enable, and often encourage, users to move around physically; they have been particularly praised for activating physically inactive individuals and providing a fun social outdoor activity [1,2]. While under normal circumstances these definitely are positive things, during the COVID-19 pandemic in 2020, people were advised to do the exact opposite: stay at home and keep social meetings to the minimum [3-6]. The entertainment industry reacted at large to the pandemic by offering various kinds of free services to consumers, increasing their motivation to stay home and avoid contracting and spreading the disease. In this context, it is particularly interesting to study the measures taken by LBG developers, and how their players reacted and responded to the situation. 
LBGs have recently gained a lot of popularity. From the perspective of multimodal technologies, they differ from traditional video games in that they use the player's physical location as a form of input that impacts the game world. The currently most popular LBG, Pokémon GO, was installed into roughly 55 million devices in 2019 [7]. The company who created the app advertises that their LBG apps have been cumulatively downloaded more than a billion times and that as many as $73 \%$ of Pokémon GO players change their regular walking routes weekly because of the game [8]. These figures give an estimate on the impact that LBGs have on human movement. The finding that LBG players change their movement patterns due to the game has also been demonstrated in academic studies [9-11]. Playing the games has been linked to increased time spent outside walking [12,13] and outdoor activity has been found to be one of the main reasons players play them $[14,15]$.

As a study context in this work, we observe the reactions of LBG developers and players during the COVID-19 pandemic. Governments globally reacted to the pandemic in the first trimester of 2020 by issuing restrictions on citizens' movement, public gatherings and meetings [16]. In addition, individuals were encouraged to adopt personal health measures such as voluntary self-isolation and washing hands [4]. As LBGs are a genre of games that are typically played socially outdoors, and people were advised or even ordered to instead stay home, a natural conflict arose. This novel situation is unclear and unexplored in scientific literature. To address this research problem, we adapt the netnography research methodology collecting data from three sources. Consequently, we divide our methodology into three parts. First, we look at measures taken by LBG developers and changes done to the games to counter the spread of the pandemic. Second, we study player responses on social media focusing on Pokémon GO (the most popular LBG) specifically, by investigating top voted posts and reading their comments in 20 posts across three separate subreddits. Finally, we look at the impact of the COVID-19 pandemic on social play in Pokémon GO by employing data from a raid group (1 February-12 May 2020) in a Finnish municipality.

The rest of this study is structured as follows. First, in the background, we discuss how LBGs influence player behaviour by reviewing the extant literature and represent the study context and related theories. We then present our research design, which is followed by the results in three sections, one for each research question. In the Discussion section, we highlight our key findings, raise discussion on the implications of our findings and present the limitations and future work for this study. We end our work with conclusions.

\section{Background}

\subsection{How Location-Based Games Influence Behaviour}

Upon looking at the extant literature on behavioural consequences of playing LBGs, a few trends can be identified. First, LBGs typically increase physical activity $[2,12,13]$ and reduce sedentary behaviour [17], based on some studies even permanently outside the gaming context [18]. Second, LBGs have implications on social well-being [1,19], increasing players' altruistic behaviour and we-intentions [20,21]. Third, playing LBGs impacts real-world movement patterns and propensity [10]. Finally, despite some reports suggesting that playing LBGs might cause players to adopt unwanted behaviours [22,23], empirical studies on the matter have shown these reports to not stand on firm ground [24].

While Riar et al. [21] found a correlation between engaging with cooperative game features and altruism, this finding can also be explained by the fact that, in Ingress, players face a strong opposing force, other human players, making cooperation necessary for individual and the team's success [25]. Furthermore, LBG teams have been shown to impact players' language adaption [25], proving the impact of social influence on player behaviour. In fact, Ewell et al. argue that the main benefit of LBGs is social-well being rather than physical exercise [1], unlike some early studies on Pokémon GO suggested [13]. Based on these findings, it is evident that social identity [26] plays a role in determining 
players' actions in addition to individual goals, and understanding the impact of social influence [27] will result in a more complete understanding of how players react to global pandemics.

The extant literature on behavioural consequences of LBGs is summarized in Table 1. While information systems journal publications favor including defined theoretical frameworks, many of the studies are published in other journals, for example medical journals, which do not emphasize theory to an equal degree. Another noticeable phenomenon is the over-representation of Pokémon GO among the observed games. While this can hurt the generalizability of the results to cover all LBGs, it does make comparing studies together easier as the studied game-context is the same in nearly all cases. Finally, while the behavioural consequences of LBGs have been studied as such, behavioural changes due to unprecedented online or offline events is yet to be explored. The COVID-19 pandemic offers us an opportunity to study this and gain insight into understanding human behaviour in this context.

Table 1. Summary of the extant literature on how location-based games influence behaviour.

\begin{tabular}{|c|c|c|c|c|}
\hline Author(s) & Game(s) & Sample & Theory & Findings \\
\hline $\begin{array}{l}\text { Alomar } \\
\text { et al. [24] }\end{array}$ & Pokémon GO & 3492 & $\begin{array}{l}\text { No overarching } \\
\text { theory }\end{array}$ & $\begin{array}{l}\text { Playing Pokémon GO does not cause players } \\
\text { to permanently adopt unwanted behaviours } \\
\text { outside the game context. }\end{array}$ \\
\hline $\begin{array}{l}\text { Barkley } \\
\text { et al. [17] }\end{array}$ & Pokémon GO & 358 & $\begin{array}{l}\text { No overarching } \\
\text { theory }\end{array}$ & $\begin{array}{l}\text { Pokémon GO encourages going outside and } \\
\text { decreases sedentary behaviour. }\end{array}$ \\
\hline $\begin{array}{l}\text { Colley } \\
\text { et al. [10] }\end{array}$ & Pokémon GO & 375 & $\begin{array}{l}\text { No overarching } \\
\text { theory }\end{array}$ & $\begin{array}{l}\text { Pokémon GO reinforces existing geographical } \\
\text { biases and influences player movement patterns. } \\
\text { The game can cause players to permanently } \\
\text { change commute routes. }\end{array}$ \\
\hline Harris [18] & Beat the Street & 1567 & $\begin{array}{l}\text { No overarching } \\
\text { theory }\end{array}$ & $\begin{array}{l}\text { Gamification-based health behaviour interventions } \\
\text { can have lasting effects with a significant portion } \\
\text { of participants maintaining physically active lifestyle } \\
\text { even two years after the intervention period is over. }\end{array}$ \\
\hline $\begin{array}{l}\text { Laato } \\
\text { et al. [25] }\end{array}$ & $\begin{array}{l}\text { Pokemon GO } \\
\text { Ingress }\end{array}$ & 178 & $\begin{array}{l}\text { Social identity } \\
\text { theory }\end{array}$ & $\begin{array}{l}\text { Pokémon GO and Ingress impact player's attitudes } \\
\text { towards game slang and can cause polarized } \\
\text { attitudes towards players on opposing teams. }\end{array}$ \\
\hline $\begin{array}{l}\text { Riar } \\
\text { et al. [21] }\end{array}$ & Ingress & 206 & $\begin{array}{l}\text { We-intention } \\
\text { Altruism }\end{array}$ & $\begin{array}{l}\text { Gameplay with cooperative features can encourage } \\
\text { altruistic behaviour and we-intentions. }\end{array}$ \\
\hline $\begin{array}{l}\text { Zach } \\
\text { et al. [19] }\end{array}$ & Pokémon GO & 405 & $\begin{array}{l}\text { No overarching } \\
\text { theory }\end{array}$ & $\begin{array}{l}\text { Playing Pokémon GO increases visiting places, } \\
\text { improves well-being and increases physical } \\
\text { activity. These were linked to enjoyment which } \\
\text { was further linked to increased intention to } \\
\text { spend money on the game. }\end{array}$ \\
\hline
\end{tabular}

LBGs can have both positive and negative impacts on players during pandemics. during COVID-19, in countries where moving outside was allowed, LBGs could still motivate exercise and provide players with a healthy and fun outdoor activity that had the potential to alleviate some of the potential psychological and physical issues, such as cyberchondria [4] or obesity [28], which may arise from spending too much time stationary and in isolation at home. On the other hand, as LBGs such as Pokémon GO motivate people to gather physically together [29], and increase pedestrian traffic in large cities, there exists the danger that the games increase social contact, and thus, unintentionally contribute to the spread of the pandemic disease. A recent study on human behaviour during COVID-19 found perceived severity of the situation and self-efficacy were found to predict adopting personal health measures, while response costs had a negative effect [4]. This further emphasises the significance of LBGs' potential to increase perceived barriers to adopt recommended health measures. However, while LBGs may be a major part of some people's lives, they remain only one factor among 
many that impact human behaviour. In such a complex landscape, a wide perspective is needed to understand the situation.

\subsection{Human Behaviour during Pandemics}

Human behaviour during pandemics is affected by both internal and external factors. The internal factors refer to those constituting personal protection motivation [30], while external factors in this context refer to government enforced measures such as quarantines and other environmental effects [31]. The external and internal factors are linked, as humans better accept governmental restrictions in case they understand and agree with them [32]. In order to keep citizens aware of the situation during pandemics, and allow them the benefit of information-based decision-making and rational action, information regarding the pandemic needs to be communicated clearly [33-35]. Reducing uncertainty this way is paramount in motivating effective individual health behaviour whilst avoiding public panic [34].

Protection-motivation theory (PMT) is perhaps the most widely used theory in explaining human behaviour during pandemics (e.g., [36-38]). The theory decomposes individual level protection motivation into consisting of threat appraisal and coping appraisal constructs [39]. Threat appraisal can be further divided into perceived severity, perceived vulnerability and anxiety, while coping appraisal is the sum of self-efficacy, response efficacy and response costs [37,39]. Studies using PMT have shown perceived severity to be one of the key factors influencing behaviour change during pandemics, while response cost can alleviate this impact $[4,36]$. In the current context of LBGs, the motivation that the games provide to break quarantine can be conceptualized to belong under coping appraisal, more precisely, in response costs. As players enjoy playing LBGs, they will inevitably feel they lose something in case they are forced to quit playing due to pandemic restrictions. Following this line of thought, the main concern about LBGs during pandemics according to PMT is that they increase players' perceived response costs to adapt individual health measures, and thus reduce their protection motivation and encourage them to go out and play instead.

Besides PMT, another similar framework often used for explaining human behaviour in situations with a looming health threat is the health belief model (HBM) [36]. While PMT is concerned about protection motivation and postulates it to be the result of threat and coping appraisal, HBM seeks to understand how health beliefs lead to action [40]. Both models typically share the construct of perceived severity and susceptibility, but instead of seeing these as antecedents to protection motivation, HBM postulates them to be at the same level with health motivation [41]. Perceived barriers, which can be seen to be closely linked to response costs in PMT, have been shown to be the most powerful dimension of HBM to explain human behaviour [40]. In this study, we select PMT as a theoretical lens which we use to analyze the collected data and understand our findings over HBM primarily because of its recent popularity [36] and because the coping appraisal constructs offer a well structured theoretical viewpoint.

\subsection{Study Context: The COVID-19 Pandemic}

The SARS-CoV-2 virus, causing the COVID-19 disease, was first detected in December 2019 in the Huabei region in China, particularly the city of Wuhan [42]. The virus has been classified as highly infectious, with some estimates of its reproduction number being as high as 3.58 if no preventative measures are taken [43]. With quarantines and travel bans, China was able to slow down the epidemic trajectory of the virus [44], but during March 2020, the virus had already spread uncontrollably outside China, which lead to the World Health Organization declaring it a global pandemic on 11 March 2020 [6].

In this study, we collect three datasets, one of them from Finnish Pokémon GO players. To this end, a brief explanation of the context of Finland during COVID-19 is needed. Finland is a northern European country that offered a suitable study case as at the start of the data collection period, February 2020, the country had still only a few confirmed cases of COVID-19 and zero confirmed 
deaths caused by the illness. After mid-March, when the pandemic situation escalated globally and the virus started spreading in Europe, the Finnish government issued the following restrictions to take place starting from 18 March onwards:

- $\quad$ Face-to-face meetings of more than 10 people are forbidden.

- $\quad$ People over the age of 70 or belonging to a risk group should self-isolate and stay at home.

- School buildings are closed and schools must move to distance education. Libraries, hobby facilities, gyms and universities are closed as well, and most public events are cancelled.

- Everyone arriving from abroad will need to immediately self-quarantine for two weeks.

- Using public transportation is heavily discouraged.

Besides these restrictions, other more minor ones were issued as well. On 27 March, the Finnish government temporarily closed Uusimaa, the area surrounding its capital city Helsinki, due to a COVID-19 outbreak until 15 April. Furthermore, on 29 March, the Finnish government ordered all restaurants to close their doors with the exception of allowing them to serve take-away food. These restrictions were in place throughout April 2020 and, except for the reopening of Uusimaa, were all still in place on 12 May 2020 when the data collection period for social LBG playing in Finland ended.

\section{Research Design}

\subsection{Research Questions and Overall Research Methodology}

We employ the netnography research methodology [45] and collect three types of data: (1) the measures taken by LBG developers during March 2020 when the COVID-19 pandemic was declared; (2) how the Pokémon GO community responded to these measures by observing social media; and (3) how the COVID-19 pandemic influenced social play frequency. The netnography research method is a specific method of ethnography that focuses on observing human behaviour through online channels such as social media [45]. As an ethnographic method, netnography is at its core participant-observation research [46]. Netnography has recently grown in popularity due to it offering practical tools for qualitative data collection and analysis, and insight for several types of research problems [47]. The method can be used for, for example, validating prior perceptions of status quo in various industry sectors [48], for understanding new emerging internet platforms and their users [49], for gaining insight on player behaviour in online games [50] and for, as in our case, understanding player community responses to in-game updates and the global pandemic situation. Table 2 summarises the data collection sources. The three part methodology is summarized in Figure 1. Accordingly, we formulate three research questions, one for each part of our method.

1. What in-game changes did LBG developers make during the COVID-19 pandemic?

2. How did LBG players respond to these changes and the pandemic in social media?

3. Did the pandemic, governmental measures and in-game changes in Pokémon GO have an impact on the frequency of social play?

Table 2. Summary of collected data.

\begin{tabular}{lcc}
\hline Data & Quantity & Collection Period \\
\hline LBG developers' responses & Seven popular LBGs & 1 January-2 April 2020 \\
Social media reactions & 20 posts and related comments & 4 March-3 April 2020 \\
Raiding frequency in a Finnish city & 1338 raids & 1 February-12 May 2020 \\
\hline
\end{tabular}




\begin{tabular}{|c|c|c|}
\hline $\begin{array}{l}\text { Observation of in- } \\
\text { game changes }\end{array}$ & $\begin{array}{l}\text { Social media } \\
\text { reactions }\end{array}$ & $\begin{array}{l}\text { Change in } \\
\text { frequency of } \\
\text { social play }\end{array}$ \\
\hline $\begin{array}{l}\text { Recording changes } \\
\text { made to seven popular } \\
\text { LBGs during March: } \\
\text { 1) Pokemon GO } \\
\text { 2) Orna } \\
\text { 3) Ingress Prime } \\
\text { 4) The Walking Dead: } \\
\text { Our World } \\
\text { 5) Minecraft: Earth } \\
\text { 6) Harry Potter: } \\
\text { Wizards Unite } \\
\text { 7) Jurassic World: Alive }\end{array}$ & $\begin{array}{l}\text { Manual curation of } 3 \\
\text { largest LBG sub- } \\
\text { reddits: } \\
\text { 1) pokemongo } \\
\text { 2) TheSilphRoad } \\
\text { 3) pokemongospoofing }\end{array}$ & $\begin{array}{l}\text { Following a raid chat } \\
\text { (1200+ members) in a } \\
\text { Finnish city and } \\
\text { recording the number of } \\
\text { unique players, } \\
\text { completed legendary } \\
\text { raids and raids with +10 } \\
\text { players during February } \\
\text { 1st-May 12th, 2020. }\end{array}$ \\
\hline
\end{tabular}

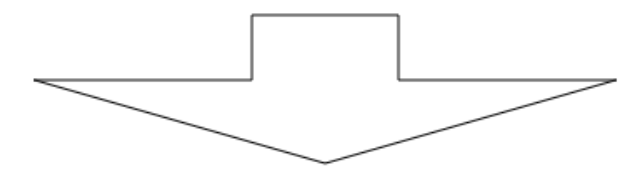

Measures taken by LBG developers during the COVID-19 Pandemic and Community Response

Figure 1. The research methodology summarized.

\subsection{Observation of In-Game Changes}

In order to answer the research question "what in-game changes did LBG developers make during the COVID-19 pandemic?" we observed social media accounts, official websites as well as in-game notifications of seven popular LBGs during March 2020 to identify whether the game developers took measures to change gameplay in order to combat the COVID-19 pandemic. The following games were selected for analysis (1) Pokémon GO; (2) Orna; (3) Ingress Prime; (4) The Walking Dead: Our World; (5) Minecraft Earth; (6) Harry Potter: Wizards Unite; and (7) Jurassic World Alive due to them being among the most popular LBGs $[7,51]$. Because of their popularity, the games were estimated to be among those having the largest influence on players' actions at a global scale. Each game was played for at least 20 hours by the authors in order to get an understanding of the game mechanics, what kinds of opportunities game designers have to influence player behavior through the games and do the games encourage behavior that should be avoided during a global pandemic, such as socializing in real world or travelling to new places.

The main source of information regarding the updates was the games' official websites and in-game news. However, social media was also followed in case we missed some news or one of the games did not have a clear website with updates. These channels were read during March 2020 regularly by the authors, with the purpose of identifying unique news and updates specifically related to COVID-19. In the popular case that news of the same update was posted on an official website, as in-game news as well as on several social media channels, the official website was preferred as a source. This was done for consistency as well as because in most cases, the social media updates linked back to the official website.

\subsection{Social Media Reactions}

In order to answer the research question: "how did LBG players respond to these changes and the pandemic in social media?", we observed social media reactions of Pokémon GO players to the in-game changes made to that game. To this end, the netnography observation and analysis method was used. When applying netnography on a specific context, the online channels that is selected for analysis needs to be (1) relevant; (2) active; (3) interactive; (4) substantial; (5) heterogeneous; and (6) data-rich [52,53]. In our case, Reddit was chosen as the platform, due to it filling the above-mentioned criteria, providing the ability to search monthly top voted posts, seeing the number of comments on each post and being able to classify them based on popularity and it being one of the most used social media platforms for structured discussion [54]. 
Three of the most popular LBG subreddits were chosen for the analysis. These were all Pokémon GO specific: (1) /r/TheSilphRoad (The largest Pokémon GO fan subreddit); (2) /r/pokemongo (Pokémon GO main subreddit); and (3) /r/pokemongospoofing (a subreddit about cheating in Pokémon GO via falsifying GPS-location). The three subreddits were varied in scope, content, rules and approach and thus diverse and suitable picks for the current study. Furthermore, as they all concerned the same game, this allowed a more in-depth view of a single game and more comparable findings across the three-part research method. A search was done on the three subreddits on 3 April 2020, sorting by the top-voted posts from the past month. This covered all posts back to 4 March 2020, a week before WHO declared COVID-19 a global pandemic. Among the top voted posts was structured discussion regarding the updates made to Pokémon GO due to COVID-19, which allowed us to investigate the players' opinions, attitudes and viewpoints on these changes. The five posts related to COVID-19 with most upvotes and related comments were selected for analysis, with the exception of the largest subreddit, /r/pokemongo, where we observed the 10 most top-voted posts because it was the largest subreddit and had the most diverse discussion on the COVID-19 topic.

Following the netnography methods [45], we read the discussion beneath the posts and made notes of points and key themes that emerged. Then, guided by the Gioia method [55], and using the theoretical lens of PMT [39], the comments were classified into 1st degree concepts in all three subreddits. After obtaining the first order concepts, these were grouped together to form 2nd order themes as guided by Gioia et al. [55]. Three constructs from PMT involved with the coping appraisal were used as aggregate dimensions through which the qualitative analysis was viewed: (1) response costs, (2) response-efficacy and (3) self-efficacy.

\subsection{Change in Frequency of Social Play}

As Pokémon GO was released in 2016 and raids were added to the game in summer 2017 [29], in February-May 2020, the raiding propensity in the game could be considered already quite stable. Raids are special location-based social events where a group of players meet at a specific physical location called a gym, which typically represent landmarks or other places of significance [11]. Once they arrived at the gym, the players join forces in battling a powerful raid boss pokémon. Should the boss be defeated by the players attending the raid, they are rewarded with items as well as with the opportunity to capture the raid boss pokémon they just defeated. The raid boss pokémon are typically rare or otherwise difficult to acquire, thus making raids highly appealing events for keen pokémon hunters. Under regular circumstances raids can be considered the main social aspect in Pokémon GO [29].

For observing whether players were playing LBGs socially during the COVID-19 pandemic, Pokémon GO was selected as it features legendary raids that typically require a team of at least five players or more to beat the boss. The data set was collected from the largest collaborative raid chat of $1200+$ members in a major city in Finland. Participants in the chat were mostly from the particular city.

The frequency of legendary raids in the case city were recorded starting on Saturday, 1 February 2020, and ending on Tuesday, 12 May 2020. This period was selected as it marks the time roughly 50 days before the Finnish government's interventions on movement took place (18 March 2020) and roughly 50 days after it. Recording the raids was accomplished by observing the largest raid chat in a selected Finnish municipality. Each unique raid reported by a player was included, and the number of players who had enrolled to participate in the given raid was also recorded. If this number exceeded 10, it was marked as a raid with 10+ people. Furthermore, for each given day, the number of unique players using the raid channel to communicate raids was recorded. It is possible that many participants joined the raids without signing up, and that several players signed up for a raid without actually joining the raid in person. Considering these limitations, the data could be used as a rough estimate depicting changes in raiding activity that happened during the course of the data collection period. Finally, to further bring meaning to this data, we invoked mobile location data from 
Google [56] and Apple [57] regarding the changes in population-level movement during COVID-19 compared to baseline, and used this data to understand and interpret our findings.

\section{Results of Measures Taken by LBG Developers}

Before presenting the measures taken by LBG developers to adjust their games to counter the COVID-19 pandemic, it is important to understand the affordances (as defined by Norman [58]) that these games have for influencing player movement and social interaction in the real world. As we played the selected LBGs and analyzed their gameplay, we identified substantial opportunities for the developers to influence player movement and social meetings via game mechanics. These are summarized in Table 3. All observed games revealed new content when the player moved to new locations in the real world. Furthermore, several games rewarded the player for walking, either by unlocking new things (e.g., Harry Potter: Wizards Unite, Pokémon GO, Jurassic World: Alive) or by increasing a number in a medal (Ingress Prime). Moving outside was further directed, for example, in Orna, where capturing territories and defending them is a big part of the game. As the territories are at fixed real-world geographical locations, travelling there is necessary for regaining control of the area. Pokémon GO, Ingress and Harry Potter: Wizards Unite have been found to further influence player movement by strategically located points of interest [11,59]. Finally, with regards to social play, some of the games never encouraged face-to-face meetings (e.g., The Walking Dead: Our World and Jurassic World: Alive) while others did it daily through several game mechanics (e.g., Pokémon GO). In summary, all of the analysed LBGs have some game mechanics motivating players to go outside, which can be seen as an opposing force to the COVID-19-related recommendations of the World Health Organization as well as many local governments around the world.

Table 3. Affordances of the seven observed LBGs for influencing player movement in the real world.

\begin{tabular}{lc}
\hline Affordance & Games Where Present \\
\hline Rewards from walking & $\begin{array}{c}\text { Pokémon GO, Ingress, } \\
\text { Jurassic World: Alive and } \\
\text { Harry Potter: wizards Unite }\end{array}$ \\
Moving reveals new content & All observed games \\
Defending territory & Ingress, Orna, Pokémon GO \\
Change walking route & All observed games \\
Encourage face-to-face meetings & Pokémon GO, Ingress, \\
& Harry Potter: Wizards Unite \\
& Minecraft: Earth \\
\hline
\end{tabular}

\subsection{Pokémon Go}

Below, we have listed the key changes to adventuring, travelling and social play that Niantic, the developer of Pokémon GO, announced to the game during March 2020. These updates are obtained from the official Pokémon GO live update website [60]:

- 12 March, Niantic cancels the social Community day event and offers bonuses relating to individual play instead such as dropping gifts from stops most frequently.

- 12 March, Niantic extends social raid event until 31 March.

- 17 March, Niantic announces the cancellation of the social event Raid Hour

- 19 March, a new in-game event requiring social play was announced lasting until 21 April.

- 23 March, Niantic announced increased daily bonuses relating to solo-play activities that do not require social interaction.

- 23 March, Niantic announced they have cancelled the planned social events: Lugia Raid Week and Raid Hour 
- 23 March, the walking requirement for battle league is removed.

- 25 March, select field research tasks that cannot be finished from home are removed.

- 30 March, John Hanke, the CEO of Niantic, publishes a blog post explaining the actions Pokémon GO has taken and plans to take to combat COVID-19.

- 31 March, the interaction distance of gyms is doubled.

There were some mixed signals from Niantic during the COVID-19 pandemic. On 12 March, we saw the first cancellation of a social event, the monthly community day event where players get together, typically with family and friends, for three hours to capture as many of a highlighted pokémon as they can. On the same day, Niantic announced that gifts would be easier to acquire from pokestops, making it less necessary to visit pokestops (and consequently, move outside); however, at the same time, the duration of a social raid event was extended. Then, again on 19 March, Niantic announced a new social raid event, but on 23 March Niantic issued further bonuses on solo-play and cancelled a few in-game social events. In addition to the above-mentioned changes, Niantic offered special bundles of poké balls in their in game shop at a radically reduced cost of one coin (in-game currency). On 31 March, Niantic announced that the interaction range for gyms is doubled, allowing players to play from home or while keeping distance to other players at raids. In their communication, Niantic never mentioned the pandemic by name, but stated instead, for example that they are making efforts to allow playing from home and allow playing while maintaining social distance, as displayed in the message in Figure 2.

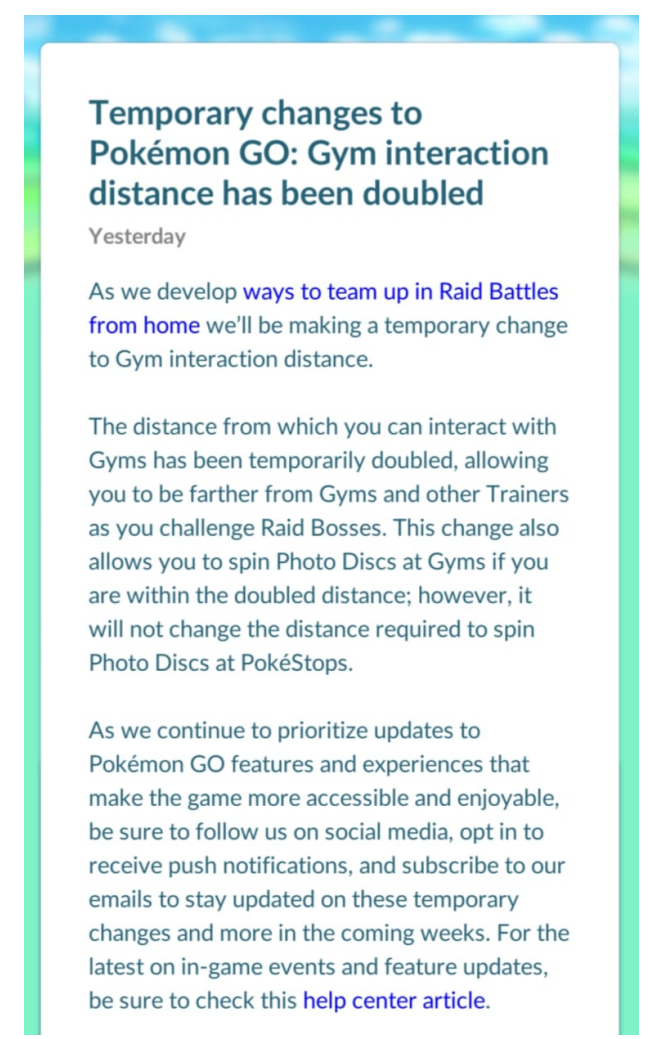

Figure 2. A screenshot taken by authors about an update issued on Pokémon GO to combat COVID-19.

\subsection{Other Location-Based Games}

In addition to Pokémon GO, we looked at measures taken by the developers of the six other LBGs. These all shared similarities to the measures taken by the developer of Pokémon GO. Changes made to the rest of the games are detailed below. 


\subsubsection{Orna}

Orna announced an event called It's dangerous out there scheduled to last until 30 March where players are advised to stay safe and are offered bonuses to an in-game activity (gauntlets) which do not require moving around but can be played from home.

\subsubsection{Ingress Prime}

On 16 March, Ingress Prime announced they have cancelled four social events: (1) First, Saturday events on 4 April are all cancelled globally; (2) All 15 Lexicon Hexathlon scheduled on 25 April are postponed; (3) Requiem Anomaly on 9 May has been postponed; and (4) NL1331X event from 9 May to 3 July has been postponed [61]. Then, three days later, on 19 March, Ingress Prime announced four changes to the game Ingress itself, encouraging solo-play and providing better opportunities for remote and stationary play. All changes were announced to be live until further notice, clearly indicating that the changes were made to mitigate the spread of COVID-19 [62]. This earned praise from the Ingress community on social media with comments such as Well done!, This is actually a pretty good update and Will there be a I survived the coronavirus medal? appearing on Twitter, Facebook and Telegram.

\subsubsection{The Walking Dead: Our World}

On 14 March, the first news on in-game changes to allow gameplay for players in lock-down due to the pandemic was introduced. On 17 March, the game announced more changes that aimed to boost the feasibility of stationary play. On 23 March, the changes supporting stationary play were reinforced and some new changes were introduced on Reddit as well as the in-game news of the Walking Dead: Our World app. The changes included: (1) A free daily Terminus Map, which supports stationary play; (2) every Friday a free additional pack that supports stationary play; (3) reduced prices on items that support stationary play and online social cooperation; (4) increased duration on items that support stationary play and online social cooperation; (5) more playing content for players that do not move; (6) better opportunities to maintain in-game structures, requiring less travelling and less playing. The developers further announced they will be closely monitoring the COVID-19 pandemic and stated that another update will follow in one week on 30 March. On this date, a new bullseye event was introduced, while keeping all the above-mentioned measures in place.

\subsubsection{Minecraft Earth}

Minecraft Earth was the last game of the seven analysed games to react to COVID-19. On 25 March, the game developers announced that they are making in-game changes due to the pandemic to "Flatten the curve", referring to reducing the exponential spread of the COVID-19 virus. Accordingly, adjustments were made to to allow playing from home by increasing Toppable spawn rates and allowing the creation of adventures anywhere.

\subsubsection{Harry Potter: Wizards Unite}

On $12 \mathrm{March}$, the game developer announced they have postponed the community day event scheduled for March 2020. On 13 March, the developers announced the following changes to gameplay:

- $\quad$ Tonic for Trace Detection will reveal Traces more frequently

- Tonic for Trace Detection will have Master Notes effectiveness increased from $15 \%$ to $50 \%$

- Ingredients will appear on the Map more frequently, especially those needed for Tonic for Trace Detection

- Traces will appear on the Map more frequently

- $\quad$ Spell Energy will appear on the Map

- A free store bundle will be available in the Diagon Alley shop featuring 4 Tonics for Trace Detection

- The amount of Gifts that can be opened each day will be increased from 10 to 20 
Moreover, on 17 March, the developers announced that Spell Energy Gifts will include increased amounts of Spell Energy. All these changes contribute to making stationary play more fun. On 26 March, the developers announced a new event, stressing in their post that the event has been reworked to support playing from home. Finally, it is noteworthy that Harry Potter: Wizards Unite contains a social play element: fortress battles. These are similar to Pokémon GO raids, where players get together to the same physical location and challenge fortresses filled with monsters. While the fortress-battles are social, they are not time-dependent the same way raids in Pokémon GO are, and can be played whenever the players choose. Perhaps because of these reasons, no adjustments were found to be made to fortress battles.

\subsubsection{Jurassic World: Alive}

On 21 March Ludia, the creator and maintainer of Jurassic World: Alive announced that they take the COVID-19 pandemic seriously but will keep all their games operational and continue to monitor the situation [63]. Simultaneously, they announced three changes to Jurassic World: Alive: (1) Adding the Giga Scent which provides three hours of stationary gameplay daily; (2) A new in-game purchase offer for Pile of Darts, which also is a step towards providing stationary play; and (3) Drone, ESD and Strike Tower range increased, making stationary playing easier. The update post regarding these changes was later updated with further information on changes made to the game to enable safer play during the pandemic. The changes were announced to be valid until May 1st.

\subsection{Summary of How LBG Developers Reacted}

Out of the seven analyzed games, all made changes to their games to reduce the spreading of the pandemic by reducing the incentives of their players to break quarantine or self-isolation. This shows that the gaming companies are quick to react to global news and are doing their part in motivating players to stay home. Despite the changes, however, many of the LBG still encourage going out to a certain degree. While playing from home was made easier and more fun, none of the games completely removed the location-based aspect of their games. Thus, a small incentive to go out and play still remained in the observed LBGs.

\section{Results on Social Media Reactions}

In addition to the in-game changes, we wanted to understand players' reactions to COVID-19 and to changes made by the LBG developers. To this end, we looked at social media responses, in particular, from three unique LBG-themed subreddits.

\section{1. /R/Pokemongo}

The / $\mathrm{r}$ /pokemongo subreddit was by far the largest LBG subreddit out there at the time of data collection with 2.4 million subscribers. While the overwhelming majority of posts and content on the subreddit are related to Pokémon GO, there is a large variance in the type of content. The subreddit typically consists of original art works, shared news, shared stories, discussion, as well as a considerable amount of Pokémon GO-related memes. The ten most upvoted COVID-related posts (4 March-3 April 2020) are displayed in Table 4.

Various memes and original art were upvoted to raise awareness of the pandemic among the Pokémon community, showing how memes and art can be used to contextualize acute real-world problems to players. The comments related to the meme posts were typically more humorous or sarcastic, for example, Reddit user "ShannieD" sarcastically wrote "Sometimes, in a global pandemic, sacrifices have to be made." (POST \#3) when commenting on a new Pokémon GO feature that was introduced to address the COVID-19 situation but which, as a trade-off, contained a hilarious bug. The comments on artworks typically showed appreciation, however, there were also clever remarks, for example, Reddit user "quickhakker" commented: “30\% of Americans won't catch that" (POST \#5) 
undoubtedly referencing the Pokémon slogan gotta catch 'em all as well as the then estimated level of people that will not get the COVID-19 disease in any case because of the effects of herd immunity.

Table 4. TOP 10 most upvoted COVID related posts on /r/pokemongo during 4 March-3 April 2020.

\begin{tabular}{|c|c|c|}
\hline Upvotes & Type of Post & Main Content \\
\hline \#1 16.1k & news & $\begin{array}{l}\text { A 77-year old Pokémon GO player in Spain gets fined for breaking quarantine } \\
\text { to play Pokémon GO. }\end{array}$ \\
\hline \#2 15.6k & meme & It is important to wear a face mask while playing. \\
\hline \#3 12.3k & meme & The change to gym encounter distance causes a bug with rocket leaders \\
\hline \#4 11.1k & meme & It is important to stay safe during the pandemic. \\
\hline \#5 9.4k & original art & A pikachu wearing a face mask. \\
\hline \#6 8.4k & discussion & Pokémon GO is the worst kind of game people should be playing during the pandemic. \\
\hline \#7 6.2k & original art & Art depicting the importance of keeping social distance while playing. \\
\hline \#8 5.5k & suggestion & Distance trading should be allowed in Pokémon GO for the duration of the pandemic. \\
\hline \#9 5.4k & suggestion & Capturing pokemon should reward extra balls to make playing from home easier. \\
\hline$\# 10$ 5.3k & news & Niantic makes in-game changes to reduce the incentive the game provides to go out \\
\hline
\end{tabular}

\subsubsection{Pokémon Go Is Not a Suitable Game for the COVID-19 Situation}

One of the central concepts that was seen at the level of the posts was that LBGs are not a suitable genre of games for the COVID-19 situation where self-isolation was advised (e.g., POST \#6). Reddit user "dontcareaboutreposts" summarized the following: "The truth is that this game [Pokémon GO] is fundamentally based on walking to achieve goals." and continued "I'm not saying we should all stop playing, I'm still planning on catching some good boys when I go out for groceries and stuff. However, just keep in mind that this game isn't designed for your lifestyle if you're stuck at home. In order to fix that, Niantic would have to change the game entirely, and we probably wouldn't like it all that much." (POST \#6). The number of upvotes $(8400+)$ on the post indicated that several players shared these sentiments. This theme was present throughout discussion in almost all posts. Responses such as "DO NOT BREAK YOUR QUARANTINE PEOPLE! Stay inside, help everybody" (POST \#1) as written by Reddit user "andion82" were commonplace.

5.1.2. LBG Developers Should Be Given Time to Make In-Game Changes and Adjust to the COVID-19 Situation

The comments on new features introduced to help the COVID-19 situation were understanding, even though there were some who criticized the slow speed in which these changes were implemented. Reddit user "macljack" was among the many who defended Niantic for at least attempting to change their game to address the COVID-19 situation: "Good lord people. This is a game which from the ground up is designed to be played outside and the developer has been working very hard to help us adjust to our current reality. If you aren't happy too bad they can't fix everything and they certainly can't make all the changes needed so fast." (POST \#2). Other comments focused on admitting that the features Niantic introduced were not perfect but were hopeful for the future. As an example, Reddit user "liluncookednoodle" stated: "I think they just messed up when extending the gym radius, probably be fixed with a later update" (POST \#3).

5.1.3. Do LBG Developers Have a Moral Responsibility to Avoid Encouraging Unwanted Behaviour during COVID-19?

Some heated discussion was held on the moral responsibility of LBG developers. Reddit user "linkkd" stated: "Now answer me: is it ok for a company to keep encouraging people to play their game that involves going out during a pandemic? While not giving people all the resources so they can keep playing from home?" (POST \#6) to which Reddit user "Mal-De-Terre" replied: "You could... you know... not play..." (POST \#6). Outside these arguments, the player community seemed highly conscious about the temptation to go out that Pokémon GO provides even in situations where it was forbidden by law, as displayed in the most top voted post about a man being fined for breaking quarantine to play Pokémon GO (POST \#1), which was condemned by the player community as being irresponsible, especially considering the 
player's old age making him belong to a high-risk category. For example, Reddit user "KeesApenvlees" commented on the situation: "Imagine going out to play a game in one of the most infected areas of the world when you're 77 years old" (POST \#1). There did not seem to be a clear consensus on whether LBGs should reduce incentives to go out and play, whether people should be able to self-regulate no matter what some games encourage and whether in fact both of these should take place.

\section{2. /R/Thesilphroad}

TheSilphRoad is a fan-driven subreddit that differs from $/ \mathrm{r} /$ pokemongo in that it does not allow the posting of memes or artwork. It can also be characterized for the meeting place of the more serious and hardcore players. The five most upvoted COVID-19 related posts (4 March-3 April) are displayed in Table 5. Compared to /r/pokemongo, TheSilphRoad subreddit had considerably fewer top voted posts related to COVID-19 and much more posts strictly relating to in-game content. This can be seen to be a consequence of the subreddit rules as well as of the players that gravitate towards the subreddit in the first place.

Table 5. Top 5 most upvoted COVID related comments on /r/SilphRoad during 4 March-3 April 2020.

\begin{tabular}{|c|c|c|}
\hline Upvotes & Type of Post & Main Content \\
\hline$\# 14.6 \mathrm{k}$ & news & $\begin{array}{l}\text { The walking requirement for GO Battle League is removed, allowing players } \\
\text { to grind it from home }\end{array}$ \\
\hline \#2 3.5k & news & $\begin{array}{l}\text { A poke ball box helping out players who cannot leave their houses to spin pokestops } \\
\text { for balls is made available }\end{array}$ \\
\hline \#3 3.1k & news & Field research tasks that cannot be finished from home are removed. \\
\hline \#4 2.2k & news & Niantic is working on more in-game updates to combat COVID-19. \\
\hline \#5 1.9k & news & $\begin{array}{l}\text { Gifts drop more easily from gyms and pokestops reducing the incentive } \\
\text { to go outside. }\end{array}$ \\
\hline
\end{tabular}

5.2.1. Pokémon Go Has Done a Good Job Minimizing Incentives It Provides Players to Break Quarantine

In all posts, commentators seemed widely accepting and even grateful to Niantic for the changes made. Comments were often informative and serious, many of them strictly game-related. As an example, comments such as "Remote Battle Requirements also lowered to Good Friends" (POST \#1) by the Reddit user "LeeDuck" were often upvoted. In addition to these informative comments, comments praising Niantic were also often upvoted. Comments such as Reddit user "transfat97's": "Niantic has honestly handled this whole situation wonderfully. I'm genuinely impressed." (POST \#1) were commonplace and were supported further by, for example, Reddit user "exatron" who wrote: "Yeah, as much flak as we give them, they're doing just about everything they can here." (POST \#1).

\subsubsection{Playing Should Not Be a Reason to Break Quarantine or Avoid Self-Isolation}

Redditors also engaged in discussion whether COVID-19 had increased or decreased playing in their area. A now deleted Reddit user posted the following "I'm actually playing more but my city is also at the beginning stages of Covid." (POST \#2). Comments were also made about the option to play during COVID-19 safely using a vehicle. For example, Reddit user "SadieSnadieSnakeyLady" wrote: "Mine has no confirmed cases but my state has started stage 1 shut downs. My partner and I just play on the way to places we have to go to. We've always been lazy car players!" (POST \#2). Some players commented saying they are in quarantine, and that they are unable to play Pokémon GO, but none showed signs of going out because of the game. For example, Reddit user "HaklePrime" wrote "Literally in quarantine right now awaiting labs, down to 8 Ultra Balls, no more poke coins, no more gifts, and in an extremely rural area. This feels like the time to quit, but I don't want to." (POST \#4). 


\subsubsection{The Pokémon Go Developer Could Have Done More}

Some commentators such as Reddit user "valdhir" raised concerns about the motivation LBGs provide to break quarantine or avoid recommended health measures by stating: "I find it odd that they still advertise giratina and timburr in raids while they are aware of the situation." (POST \#1) which was upvoted a lot and echoed by users such as "PeterCosmos" who wrote "At least I'm not the only one finding it weird that they postpone a few things but still advertise raid hours" (POST \#1). This discussion concerning the contradictory nature of Niantic's actions was slightly polarizing among Reddit users, as, when sorting the comments by "controversial", several of these comments appeared.

Two themes arose with regard to actions that Niantic could take to combat the pandemic situation. The one that was more popular among Reddit voters was the removal or reduction of social features, which was supported by several commentators and posts. As an example, Reddit user "GimmeCatScratchFever" argued for completely removing the in-game social features by posting: "I think they should scale everything down to solo able." (POST \#1). Another way that players suggested combatting the pandemic was to allow playing of all Pokémon GO's features while being stationary. For example, Reddit user "MarsNeedsFreedomToo" wrote: "Extending the range of gyms and pokestops that are within viewing distance would help with the current situation and make it easier to get and do field research/gift/raid from home." (POST\#3). However, these suggestions also received critique. For example, Reddit user "smilesbuckett" wrote: "You basically want them to just enable spoofing for everyone? How do you imagine your idea realistically playing out?" (POST \#1).

\section{3. /R/Pokemongospoofing}

The third and final subreddit we analyzed (4 March-3 April) was the third largest LBG subreddit that focused exclusively on one form of cheating in Pokémon GO, spoofing. Spoofing refers to location-spoofing, that is, falsifying the geographical location of the phone with software. The subreddit is peculiar as it consists mostly of individuals justifying their chosen form of cheating and sharing advice and experiences with others on how to avoid getting caught. The five top voted posts concerning COVID-19 during the indicated time period are shown in Table 6.

Table 6. TOP 5 upvoted comments on /r/pokemongospoofing.

\begin{tabular}{llc}
\hline Upvotes & Type of Post & Main Content \\
\hline 483 & discussion & "Ironic turn of events don't ya think Niantic?" about the COVID-19 situation. \\
480 & discussion & "Spoofing is a great way to enjoy Pokemon GO while staying safe from Coronavirus" \\
458 & discussion & "Imagine how dumb Niantic feels" about spoofing and COVID-19. \\
304 & discussion & Title: "A note for Niantic..." about how spoofing in Pokémon GO is an excellent thing. \\
276 & discussion & "It looks like Covid19 is responsible for niantic fixing their broken game". \\
\hline
\end{tabular}

\subsubsection{Rejoicing of LBG Developers Loss of Revenue Due to COVID-19}

Compared to the previous two subreddits, the commentators on this subreddit seemed to have a hostile attitude towards the developer Niantic, perceiving them as their enemy. Top-voted posts and comments more often than not made fun of the game developer and rejoiced in the possibility of them losing revenue due to the pandemic. Comments such as "Hilarious. They're handing out free incense to keep us home but won't unlock suspended accounts and will probably double down on spoofers. Oh the irony!" (POST \#1) by Reddit user "skiermama" appeared often. Some users seemed more neutral, for example, Reddit user "Dyllamo" wrote "it really sucks bro. $i$ don't think niantic will change their minds on people spoofing but at least they gave us lure modules and increased wild spawn rates. i miss spoofing tho" (POST \#1). As indicated by the two quotes above, most of the content in this subreddit was about spoofing in Pokémon GO. Hence, the hostile attitude towards the game developer might be caused by the frequent bans players seem to be getting. This was exemplified by the Reddit user "AngeloPika" who wrote: "Niantic made a mistake chasing down spoofers like they did. However that's not my problem anymore. I stopped 
playing 1 month ago after my 4 accounts got 7 and/or 30 days ban. Believe me their are lots of other games and much much cheaper. Take care everyone" (POST \#1).

\subsubsection{The COVID-19 Situation Disturbs Playing}

Users of this subreddit were exclusively stationary/remote players to begin with, as evidenced by the topic of the subreddit being "spoofing", meaning the movement restrictions of COVID-19 likely had minimal impact on their playing. Surprisingly, however, some comments indicated that even spoofers were influenced by the COVID-19 situation. Primarily, they could not complete legendary raids requiring the attendance of five or more players because people seemed to have stopped going to these social mini-events. For example, Reddit user "kiymon" wrote "However, not even so it's fun to play legit. Not a single 5 star raid I've done because no ones there to play. It's so boring that I have decided to quit playing. Well I think for me it's over. No spoofing, no playing." (POST \#1)

\subsubsection{Playing Should Not Be a Reason to Break Quarantine or Avoid Self-Isolation}

Despite the hostility towards Niantic, the subreddit contained several comments encouraging people to stay safe, stressing that health and safety were more important than any game. For example, the Reddit user "joinedthedarkside" commented "I just would like to say one thing and it doesn't matter if you're a spoofer like me, or a legit as I once was. Be careful with Covid 19. It's much more than a flu. Stay safe, wear a mask, always wash your hands, don't shake hands, avoid at any cost crowds and don't be that jerk that goes to the supermarket and buys all the food and toillet paper. We are all in this together despite our diferences." (POST \#3). In addition, humor was present, as some commentators including "Mr_MustachioWhat" joked: "Coronavirus was launched by spoofers for getting their accounts suspended" (POST \#5). These kinds of comments were received lightheartedly by other Reddit users and upvoted frequently.

5.3.4. LBG Developers Have a Responsibility to Minimize the Impacts Their Game Has on Unwanted Pandemic Behavior

The posts also contained interesting discussion regarding cheating (spoofing) being the ethical choice not only during the pandemic, but also outside it, as several Pokémon GO players were claimed to be driving around with their cars causing $\mathrm{CO}_{2}$ emissions and accelerating climate change. Spoofing was defended also specifically in the COVID-19 context. For example, the Reddit user "Anyab8383" wrote "I enjoy playing legit when I can leave, but this is a literal public health crisis." (POST \#4) and the Reddit user "jigu1996" wrote "Thats why we spoof. Prevention is better than cure" (POST \#2). Niantic was bashed for banning several spoofing accounts just on the verge of the pandemic, with some posts claiming that they are actively encouraging people to not play remotely and go outside by banning spoofers. Ultimately while approaching the problem from a different angle, these comments shared the sentiments of the many players who commented in the other subreddits that LBG developers have a responsibility at some level (moral or ethical) to discourage unwanted behaviour during COVID-19 if possible.

\subsection{Identified Themes and Aggregate Dimensions}

Bringing together the results of conducted analysis across all three subreddits, we grouped central themes found in comments together to form 2nd order themes (see Figure 3). We have excluded from this analysis some of the themes related to spoofing, as we decided they did not concern LBGs' influence on human movement, as the comments, due to cheating, viewed Pokémon GO as a non-location-based game. Overall, based on the social media reactions, LBG developers can help with the COVID-19 situation with the measures they have taken. The two main ways they could have an impact were: (1) reduced incentives to socialize; and (2) more options for stationary playing. 


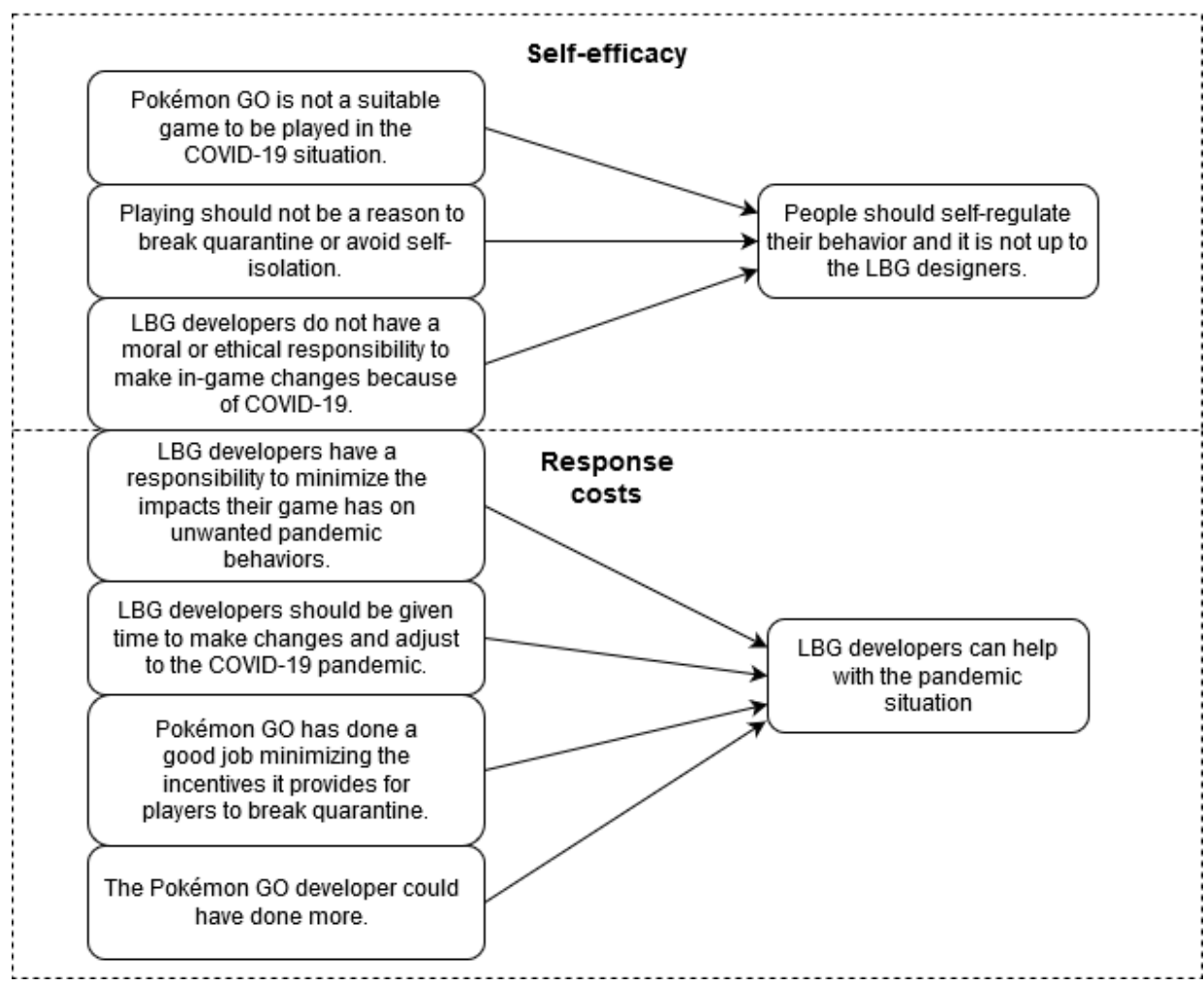

Figure 3. The main themes of the social media analysis grouped into second order themes.

Looking at our results through the lens of PMT, they are connected to the often used coping appraisal constructs response efficacy and response costs [39]. The motivation LBGs provide players to go out during pandemics increases response costs, which lowers protection motivation. On the other hand, commentators were convinced that self-isolation was the responsible thing to do, which created tensions between LBGs influence and recommended health measures. Commentators had a strong response efficacy with regard to self-isolation, while they experienced also strong response costs for not being able to play. This tension leads to two 2nd order themes, which describe as solutions that players suggested to the situation: (1) LBG developers should make changes to their games to reduce response costs of players adopting recommended health measures to combat COVID-19; and (2) Players should be able to self-regulate their behaviour regardless of the LBG influence.

In Figure 3, we have outlined how the 1st order concepts and 2nd order themes fit in the larger viewpoint of PMT. LBG developers have the possibility to reduce response costs of players, which the LBG developers did as evidenced by the observed in-game changes done due to COVID-19. On the other hand, the other commentators stressed individual responsibility and the role of self-efficacy in the following recommended health behaviour regardless of LBG influence. To summarize, LBGs are concerned with the coping appraisal aspect of PMT and the three constructs of self-efficacy, response-efficacy and response costs are needed to understand their influence.

\section{Results on Observation of Social-Play during the COVID-19 Pandemic}

We have now presented the results of our exploration on the measures taken by LBG developers as well as social media responses of Pokémon GO players. To investigate whether the pandemic and the measures taken by developers had an impact on social play frequency, we observed Pokémon GO players' participation in legendary raids in a Finnish municipality during 1 February-12 May 2020. When looking at Figure 4, we see two major peaks which both correlate with in-game rewards, mainly the availability of the legendary pokémon Darkrai in raids and its shiny form (available 6-8 March 
and again 28 April-5 May). The COVID-19 pandemic does not seem to have a significant effect on the raiding activity, even though it might be possible that as spring arrived in the observed municipality, the better outdoor weather had an opposing impact to the self-isolation recommendation related to COVID-19, and increased players' motivation to play.

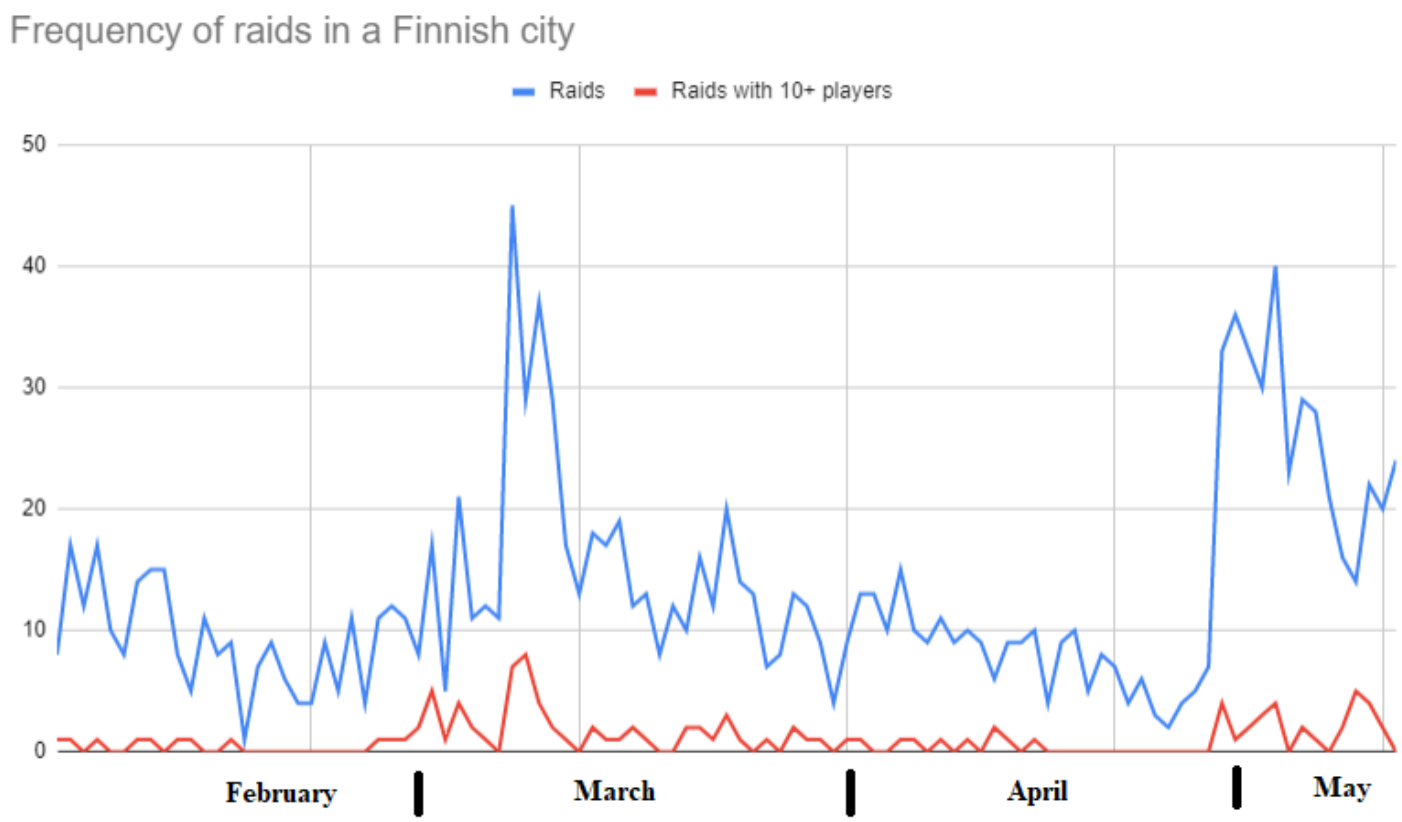

Figure 4. Displaying the changes in daily number of legendary raids organized in the largest public raid chat in a Finnish city during 1 February-12 May 2020. Each column in the figure corresponds to 20 days.

As we are concerned in particular with how government-issued restrictions impacted raiding activity, we focus on the time period of five days before (12 March-16 March) the Finnish government's intervention and five days afterwards (18 March-22 March). In the time period, five days before the limitations were issued there were 79 raids with seven containing more than 10 people, and in the time period five days after we recorded 70 raids with eight containing more than 10 people. Both of these numbers include a weekend; however, things such as weather and the changing in-game rewards might have still impacted these numbers. Still, we conclude based on this data that the government's call to limit social meetings and banning meetings of over 10 people had no impact on raiding culture in the case of a municipality in Finland. Finally, when observing the geographical location of the raids, no significant change towards an increased number of rural area raids was recorded and a majority of the raids throughout the observed time period took place near the city center.

To better understand our findings in light of the effects of COVID-19 on human mobility, we look at the Google [56] and Apple [57] COVID-19 mobility reports. The Google data shows the current trend between 26 March-7 May compared to baseline and the Apple data show movement data from 13 January until 12 May. Both reports showed a roughly 50\% decrease in the use of public transport in Finland due to COVID-19 in late March. The Apple data also show a 24\% decrease in outdoor walking in this time period. These changes persisted up until May where the data collection period ended, however with a slightly increasing trend towards the baseline. Surprisingly, the Google data show that the use of parks and recreational grounds has gone up by roughly $90 \%$ from baseline due to COVID-19 while visiting retail stores has gone down roughly $30 \%$. This implies that people moved in general away from busy areas into parks and possibly sub-urban areas where they live. When comparing the population-level movement data from Google and Apple to our data, there does not seem to be any connection. A similar change in mobility that was demonstrated in the population level could not be seen among LBG players. This indicates that LBG play could be obsessive or seriously habituated 
behaviour that persists over real world changes, despite the games being played under the laws and regulations of the real world. Accordingly, it shows that LBG developers have major influence over players' actions, and simple things such as in-game digital rewards can be used to move players around in the real world.

\section{Discussion}

\subsection{Key Findings}

We summarize our findings for each research question as follows:

- What in-game changes did LBG developers make due to the COVID-19 pandemic?

Out of the seven observed games, all introduced in-game changes to support stationary play and to reduce the temptation the game causes to go out, explore and socialize. The first in-game changes were reported on 12 March on Pokémon GO, with several games making even more changes afterwards. The last game to take COVID-19 into account was Minecraft: Earth which was updated on 25 March. Perhaps the most notable and controversial case was Pokémon GO, which despite cancelling social events and increasing stationary gameplay via several changes, still announced new legendary raids on 19 March at which point most of European countries and the United States were already advising people to stay indoors and avoid social contact if possible.

- How did LBG players respond to these changes and the pandemic in social media?

The social media thematic analysis revealed two main 2nd order themes: (1) LBG developers can help with the on-going pandemic situation; and (2) People should self-regulate their behaviour and it is not the LBG designers and developers responsibility to intervene. These themes were connected to the coping appraisal construct of PMT, mainly response costs and self-efficacy, respectively. Players also demonstrated a high response efficacy with regard to self-isolation and were thankful that LBG developers took measures to reduce players' response costs of adopting the recommended health measures amidst the COVID-19 pandemic.

- Did the pandemic, governmental measures and in-game changes in Pokémon GO have an impact on the frequency of social play?

Contrary to what was expected based on the rest of the analysis, the observed raid chat indicated that during 1 February-12 May 2020 in Finland, players' behaviour was overwhelmingly more impacted by the LBGs rewards than COVID-19. A focused observation of player behaviour five days before and after the Finnish government issued restrictions on meetings showed no difference in social play activity. These findings, while limited by the sample, indicate that LBG developers have significant influence over their player population's movement, which they can manipulate with available digital raid rewards.

The individual findings of our three-part methodology can be connected together using PMT [39]. Assuming LBGs do not influence their players' threat appraisal, we only focus on the coping appraisal. As mentioned, coping appraisal can be divided into self-efficacy, response efficacy and response costs [37]. The finding that players did not raid less even after government issued limitations on social meetings can be understood by looking at the tension between the coping appraisal constructs. In the case of response- and self-efficacy, players may feel they are generally able to socially distance themselves from others at raids while playing, and being able to comply with the recommended one metre distancing rule suggested by the World Health Organization [64]. As the data for social play came from a raid log, we did not record how players positioned themselves during actual raids. It is also possible that players valued the response costs of having to quit playing too high for them to avoid recommended health measures, mainly self-isolation. In fact, a recent study on why people self-isolate during COVID-19 found response costs to negatively influence self-isolation intention [4]. LBG developers managed to reduce the response costs for their players of adopting recommended health measures via the in-game changes they made. 
Besides coping appraisal, the other part of PMT, threat appraisal, also deserves to be looked at in our context. Even if LBGs do not influence their players' perceived severity or susceptibility, during COVID-19, these still played a role in players' actions. It is possible that the players did not yet perceive COVID-19 to be an accurate threat to them during the data collection period. However, the population-level mobility trends of Google [56] and Apple [57] showed clear changes in human movement; this was not shown in the data we collected. On the other hand, while the Finnish government had issued a recommendation to avoid extra social contact, no reinforcement of this rule was yet in place, meaning it was not illegal to go out and play. during the observed time period, the number of active COVID-19 cases in Finland remained constantly below a thousand, contributing to people perhaps not perceiving it as an immediate threat to them.

\subsection{Implications of the Findings}

Our results highlight LBG developers' ability to influence player movement also during pandemic situations. This has practical implications on gamification literature [65] and serious game literature $[2,66]$. The social media analysis showed LBG players to experience response costs for not being able to play, and suggested two solutions to the situation: (1) game developers could alleviate the perceived response costs by making in-game changes; and (2) players should better self-regulate their behaviour. With these findings, we contribute to the literature of LBGs' ability to influence players and specifically their movement $[10,59,67]$. Our findings also demonstrate how game developers seem to be increasingly monitoring the global situation and are quick to react and adjust their gameplay to take into account new situations. This highlights a trend where games today are updated regularly and consequently changing and evolving constantly.

One of the questions that remains unanswered is why LBG developers were so quick to react to COVID-19 with in-game changes. We give three possible reasons: (1) Governments issued quarantines forbidding players to move outside, forcing LBG developers to react quickly in order to not lose these players as customers; (2) LBG developers were genuinely concerned about people's health and safety; and (3) as LBGs are marketed as games for health, the developers did not want to end up in news articles for motivating people to break quarantine (even though this still happened, as indicated by them most upvoted post on observed subreddits). It is possible that all three reasons were simultaneously at play, influencing different LBG developers to varying degrees. The first point might at least have a lot of weight, as demonstrated by the on-going competition of game developers to motivate people to stay home. In fact, several other developers and publishers of multiplayer and single player games provided special events, prizes and offers to players during the pandemic with the goal of encouraging people to stay indoors. For example, the Belarusian-based company Wargaming offered 14 days of premium membership to all its players in their games World of Tanks, World of Warships and World of Warplanes, which gives players more rewards from playing and consequently makes playing feel more worthwhile [68]. As another example, Ubisoft provided a number of games for free, such as Child of Light, Assassin's Creed Odyssey, Rayman Legends, during a limited period to encourage people to stay at home and play [69]. Additionally, 18 game industry leaders launched the \#PlayApartTogether campaign which aimed to promote the World Health Organization's important messages and guidelines with regard to COVID-19, thus slowing down the spread of the virus [70]. Among these industry leaders were the companies Unity Technologies, Activision, Blizzard, Zynga, YouTube, Riot Games and Twitch, who together have access to a significant number of players worldwide.

The changes made to the LBGs seemed to primarily focus on the two aspects also present in the social media analysis: (1) stationary play and (2) reduced social play. For example, Niantic wrote in one of their updates "As we develop ways to team up in Raid Battles from home..." [60] combining both these goals, allowing players to play from home while in quarantine but also participate in the social activities (raids) while maintaining self-isolation. This raises the question regarding the emergence of new gameplay norms and how COVID-19 might have permanently impacted LBG design and 
gameplay. In fact, some of the changes that were made to take COVID-19 into account are likely to remain in the LBGs even after the pandemic situation is over. Taking Pokémon GO as an example, remote raid passes were added to the game which are a permanent game mechanic. Another aspect is how the COVID-19 situation might have permanently impacted player propensity. As players can adopt new ways to play because of COVID-19, returning to the old ways might take time or not happen at all. Studies have already begun investigating what are the possible long-term effects of COVID-19 on, for example, small businesses [71] and trading [72]. However, we believe the impacts on LBGs will not be as substantial, as evident by our findings that COVID-19 had minimal impact on players' social play in the observed municipality in Finland.

\subsection{On Moral Responsibility of the Gaming Industry}

According to Statista, the number of active gamers worldwide is estimated to be 2.6 billion in 2020 [73]. Upon global threats, such as the COVID-19 pandemic, the actors in the gaming industry thus have a significant power, as well as arguably a moral responsibility, to convey important information and use games to influence this massive group of individuals. In the case of COVID-19, this means, for example, to cancel public events (e.g., fairs and e-sports tournaments) and to convince players to stay indoors by offering them various incentives. The moral responsibility of LBG developers is even greater, as their players' actions can directly influence the development of the pandemic. It is therefore important to discuss to what extent the developers of popular LBGs have accepted their moral responsibility and provided sufficient measures to combat the pandemic.

Our findings suggest that a majority of the LBG developers employed various means to facilitate a change in player behaviour towards staying indoors, but ultimately leaving a lot of responsibility to the players. LBGs are played within the limits of government enforced laws and players should not under any circumstances raise above them, nor should LBGs motivate breaking the law. Before the COVID-19 pandemic, the laws and rules on how to play LBGs were fairly uniform globally, but the pandemic introduced a situation where some parts of the world went into lockdown forbidding unnecessary outdoor activity while other areas remained open. This new challenging situation and the rapid phase with which it was introduced to the LBG developers left little room to design careful solutions to the problem. The social media analysis showed that LBGs can support and help individuals adopt recommended health measures and decrease the incentives they provide to avoid self-isolation, but also that it ultimately remains the individuals' responsibility to abide by the law and adopt recommended health measures. However, the question remains whether LBGs encouraged illegal or irresponsible behaviour during COVID-19. Our findings show this was the case to a minor degree as demonstrated by the social media analysis.

\subsection{Limitations and Future Work}

Our work has methodological limitations in all three parts. First, in retrieving information on in-game changes, we used official websites when available but also social media channels. It is possible that we still missed some updates as the search was not systematic across all games due to varying communication methods by the different companies. Second, with regard to the social media analysis, we used netnography [45] and the authors perceptions and knowledge of the games and the community to evaluate the public response. As such, the analysis and understanding of the situation was to a degree dependent on the authors' viewpoints and experiences. The social media search was also limited by the chosen platform, which in our case was Reddit, and, more specifically, three Pokémon GO subreddits. Other social media channels, for example, less polarizing ones or those open to more critique, may have given other kinds of results. Third, the social playing activity observation had also its limitations. We looked at the most popular raid chat in a single municipality during a time when there were no restrictions on moving outside in place. The findings might suffer from geographical and cultural limitations, and it remains unclear whether they are representative on a global sale. The used raid chat measured intentions to participate in raids, but not for all players. 
Thus, the data are missing a proportion of players who did not use the raid chat as well as it does not confirm whether the reported raids took place in the end or not.

While our findings demonstrated that LBGs influence player behaviour during pandemics, it remains unclear whether the players still playing would be going out without the motivation provided by the LBGs. Further research is encouraged on this topic. More specifically, future work could measure PMT constructs such as perceived severity [74], perceived vulnerability [75] as well as game addiction [76] and deficient self-regulation [77], and look how these relate to the intention to self-isolate during pandemics [4]. The findings of the current study could also be supplemented by studies on human behaviour during pandemics generally, relating player behaviour to what is considered normal and measuring whether there exists statistical differences in likelihood of breaking quarantine for LBG players compared to others. The findings of such study could be used by governments to understand and control human actions during pandemics. Studies could look into how the motivations and gratifications of LBG players changed during COVID-19. One other avenue for future work is looking at the playing locations during pandemics, which LBGs have specifically been shown to be able to impact $[10,11,59]$. Despite us not finding differences in the geographical locations of raids in the observed chat, there might exist variance in geographical location of other kind of playing such as egg hatching. Finally, it could be explored how LBGs could gamify social isolation, rewarding players for spending time in exclusive isolated environments.

\section{Conclusions}

Our findings demonstrate that LBG developers were quick to react to the COVID-19 pandemic. Furthermore, the empirical data on raid attendance collected among Pokémon GO players in Finland showed that players' gameplay was impacted more by offered in-game rewards in LBGs than the COVID-19 pandemic. While the game companies received mostly praise for the made in-game changes in social media, there were suggestions and calls for further action. This raises ethical concerns regarding the duty of LBG developers to minimize health risks, and whether government and health officials should even take LBGs into account or use them to their advantage when designing health interventions. The idea that LBGs acted to a small degree as catalysts of COVID-19 propagation is rather paradoxical given their underlying motive of improving the health of their players. Time will show how the pandemic will advance and future studies may reveal more information on the involvement of LBGs in the complex equation of containment, or spreading, of the virus.

Author Contributions: Conceptualization, S.L.; methodology, S.L. and A.K.M.N.I.; investigation, S.L. and T.H.L.; resources, S.L.; data curation, S.L.; writing-original draft preparation, S.L. and T.H.L.; writing-review and editing, S.L., T.H.L. and A.K.M.N.I.; visualization, S.L.; supervision, T.H.L. and A.K.M.N.I.; All authors have read and agreed to the published version of the manuscript.

Funding: This research received no external funding.

Acknowledgments: We would like to thank our families who spared a lot of time for us to work on this manuscript during COVID-19 quarantine. We would also like to express our thanks to the editor and the reviewers for their insightful and thoughtful feedback and improvement suggestions.

Conflicts of Interest: The authors declare no conflict of interest.

\section{Abbreviations}

The following abbreviations are used in this manuscript:

LBG Location-based Games

PMT Protection-motivation theory

HBM Health belief model

GPS Global positioning system

COVID-19 Coronavirus disease 2019 


\section{References}

1. Ewell, P.J.; Quist, M.C.; Øverup, C.S.; Watkins, H.; Guadagno, R.E. Catching more than pocket monsters: Pokémon Go's social and psychological effects on players. J. Soc. Psychol. 2020, 160, 131-136. [CrossRef] [PubMed]

2. Laato, S.; Hyrynsalmi, S.; Rauti, S.; Islam, A.N.; Laine, T.H. Location-based Games as Exergames-From Pokémon To The Wizarding World. Int. J. Serious Games 2020, 7, 79-95. [CrossRef]

3. Anderson, R.M.; Heesterbeek, H.; Klinkenberg, D.; Hollingsworth, T.D. How will country-based mitigation measures influence the course of the COVID-19 epidemic? Lancet 2020, 395, 931-934. [CrossRef]

4. Farooq, A.; Laato, S.; Islam, A.N. Impact of Online Information on Self-Isolation Intention during the COVID-19 Pandemic: Cross-Sectional Study. J. Med Internet Res. 2020, 22, e19128. [CrossRef] [PubMed]

5. Hellewell, J.; Abbott, S.; Gimma, A.; Bosse, N.I.; Jarvis, C.I.; Russell, T.W.; Munday, J.D.; Kucharski, A.J.; Edmunds, W.J.; Sun, F.; et al. Feasibility of controlling COVID-19 outbreaks by isolation of cases and contacts. Lancet Glob. Health 2020. [CrossRef]

6. Organization, W.H. Coronavirus Disease 2019 (COVID-19): Situation Report, 51; World Health Organization: Geneva, Switzerland, 2020.

7. Chapple, C. Pokémon GO Has Best Year Ever in 2019, Catching Nearly \$900 Million in Player Spending. Available online: https:/ / sensortower.com/blog/pokemon-go-has-best-year-ever-in-2019-catching-nearly900m-usd-in-player-spending (accessed on June 16th, 2020).

8. Niantic. Make an Impact with Location-Based AR Marketing. Available online: Https://Nianticlabs.com/ business / (accessed on 3 March 2020).

9. Andone, I.; Blaszkiewicz, K.; Böhmer, M.; Markowetz, A. Impact of location-based games on phone usage and movement: A case study on Pokémon GO. In Proceedings of the 19th International Conference on Human-Computer Interaction with Mobile Devices and Services, Vienna, Austria, 4-7 September 2017; pp. 1-8. [CrossRef]

10. Colley, A.; Thebault-Spieker, J.; Lin, A.Y.; Degraen, D.; Fischman, B.; Häkkilä, J.; Kuehl, K.; Nisi, V.; Nunes, N.J.; Wenig, N.; et al. The geography of Pokémon GO: Beneficial and problematic effects on places and movement. In Proceedings of the 2017 CHI Conference on Human Factors in Computing Systems, Denver, CO, USA, 6-17 May 2017; pp. 1179-1192. [CrossRef]

11. Laato, S.; Pietarinen, T.; Rauti, S.; Laine, T.H. Analysis of the Quality of Points of Interest in the Most Popular Location-based Games. In Proceedings of the 20th International Conference on Computer Systems and Technologies, Ruse, Bulgaria, 21-22 June 2019; pp. 153-160. [CrossRef]

12. Althoff, T.; White, R.W.; Horvitz, E. Influence of Pokémon Go on physical activity: Study and implications. J. Med Internet Res. 2016, 18, e315. [CrossRef]

13. Laato, S.; Hyrynsalmi, S.; Rauti, S.; Sutinen, E. The Effects Playing Pokémon GO has on Physical Activity-A Systematic Literature Review. In Proceedings of the 53rd Hawaii International Conference on System Sciences, Maui, HI, USA, 7-10 January 2020. [CrossRef]

14. Alha, K.; Koskinen, E.; Paavilainen, J.; Hamari, J. Why do people play location-based augmented reality games: A study on Pokémon GO. Comput. Hum. Behav. 2019, 93, 114-122. [CrossRef]

15. Hamari, J.; Malik, A.; Koski, J.; Johri, A. Uses and gratifications of Pokémon Go: Why do people play mobile location-based augmented reality games? Int. J. Hum.-Comput. Interact. 2019, 35, 804-819. [CrossRef]

16. Cucinotta, D.; Vanelli, M. WHO declares COVID-19 a pandemic. Acta Bio-Med. Atenei Parm. 2020, 91, 157-160. [CrossRef]

17. Barkley, J.E.; Lepp, A.; Glickman, E.L. "Pokémon Go!" may promote walking, discourage sedentary behavior in college students. Games Health J. 2017, 6, 165-170. [CrossRef]

18. Harris, M.A. Maintenance of behaviour change following a community-wide gamification based physical activity intervention. Prev. Med. Rep. 2019, 13, 37-40. [CrossRef] [PubMed]

19. Zach, F.J.; Tussyadiah, I.P. To catch them all-the (un) intended consequences of Pokémon GO on mobility, consumption, and wellbeing. In Information and Communication Technologies in Tourism 2017; Springer: Berlin/Heidelberg, Germany 2017; pp. 217-227. [CrossRef]

20. Morschheuser, B.; Riar, M.; Hamari, J.; Maedche, A. How games induce cooperation? A study on the relationship between game features and we-intentions in an augmented reality game. Comput. Hum. Behav. 2017, 77, 169-183. [CrossRef] 
21. Riar, M.; Morschheuser, B.; Hamari, J.; Zarnekow, R. How game features give rise to altruism and collective action? Implications for cultivating cooperation by gamification. In Proceedings of the 53rd Hawaii International Conference on System Sciences, Manoa, HI, USA, 7-10 January 2020. [CrossRef]

22. Serino, M.; Cordrey, K.; McLaughlin, L.; Milanaik, R.L. Pokémon Go and augmented virtual reality games: A cautionary commentary for parents and pediatricians. Curr. Opin. Pediatr. 2016, 28, 673-677. [CrossRef] [PubMed]

23. Wagner-Greene, V.R.; Wotring, A.J.; Castor, T.; Kruger, J.; Mortemore, S.; Dake, J.A. Pokémon GO: Healthy or harmful? Am. J. Public Health 2017, 107, 35. [CrossRef]

24. Alomar, N.; Alsaleh, M.; Alarifi, A. Behavioral consequences of Pokemon GO: The exaggerated picture. Comput. Hum. Behav. 2019, 90, 223-245. [CrossRef]

25. Laato, S.; Inaba, N.; Paloheimo, M. The Effect of Team Choice in Ingress and Pokémon GO for Players' Social Circles and Attitudes Towards Game Slang. In Proceedings of the 53rd Hawaii International Conference on System Sciences, Maui, HI, USA, 7-10 January 2020. [CrossRef]

26. Hogg, M.A. Social identity theory. In Understanding Peace and Conflict through Social Identity Theory; Springer: Berlin/Heidelberg, Germany 2016; pp. 3-17. [CrossRef]

27. Kelman, H.C. Compliance, identification, and internalization three processes of attitude change. J. Confl. Resolut. 1958, 2, 51-60. [CrossRef]

28. Rundle, A.G.; Park, Y.; Herbstman, J.B.; Kinsey, E.W.; Wang, Y.C. COVID-19 Related School Closings and Risk of Weight Gain Among Children. Obesity 2020. [CrossRef]

29. Bhattacharya, A.; Windleharth, T.W.; Ishii, R.A.; Acevedo, I.M.; Aragon, C.R.; Kientz, J.A.; Yip, J.C.; Lee, J.H. Group Interactions in Location-Based Gaming: A Case Study of Raiding in Pokémon GO. In Proceedings of the 2019 CHI Conference on Human Factors in Computing Systems, Scotland, UK, 4-9 May 2019; pp. 1-12.

30. Sharifirad, G.; Yarmohammadi, P.; Sharifabad, M.A.M.; Rahaei, Z. Determination of preventive behaviors for pandemic influenza A/H1N1 based on protection motivation theory among female high school students in Isfahan, Iran. J. Educ. Health Promot. 2014, 3. [CrossRef]

31. Maier, B.F.; Brockmann, D. Effective containment explains sub-exponential growth in confirmed cases of recent COVID-19 outbreak in Mainland China. arXiv 2020, arXiv:2002.07572.

32. Cowper, A. COVID-19: Are we getting the communications right? BMJ 2020, 368. [CrossRef]

33. Fumento, M. Fuss and feathers: Pandemic panic over the avian flu. In Weekly Standard; Terry Eastland: Washington, DC, USA, 2005; Volume 11.

34. Jones, S.C.; Waters, L.; Holland, O.; Bevins, J.; Iverson, D. Developing pandemic communication strategies: Preparation without panic. J. Bus. Res. 2010, 63, 126-132. [CrossRef]

35. Laato, S.; Islam, A.; Islam, M.N.; Whelan, E. What Drives Unverified Information Sharing and Cyberchondria during the COVID-19 Pandemic? Eur. J. Inf. Syst. 2020. [CrossRef]

36. Bish, A.; Yardley, L.; Nicoll, A.; Michie, S. Factors associated with uptake of vaccination against pandemic influenza: A systematic review. Vaccine 2011, 29, 6472-6484. [CrossRef] [PubMed]

37. Teasdale, E.; Yardley, L.; Schlotz, W.; Michie, S. The importance of coping appraisal in behavioural responses to pandemic flu. Br. J. Health Psychol. 2012, 17, 44-59. [CrossRef] [PubMed]

38. Williams, L.; Rasmussen, S.; Kleczkowski, A.; Maharaj, S.; Cairns, N. Protection motivation theory and social distancing behaviour in response to a simulated infectious disease epidemic. Psychol. Health Med. 2015, 20, 832-837. [CrossRef] [PubMed]

39. Rogers, R.W.; Prentice-Dunn, S. Protection Motivation Theory; Plenum Press: New York, NY, USA 1997.

40. Janz, N.K.; Becker, M.H. The health belief model: A decade later. Health Educ. Q. 1984, 11, 1-47. [CrossRef]

41. Rosenstock, I.M. The health belief model and preventive health behavior. Health Educ. Monogr. 1974, 2, 354-386. [CrossRef]

42. Epidemiology Working Group for NCIP Epidemic Response, Chinese Center for Disease Control and Prevention. The epidemiological characteristics of an outbreak of 2019 novel coronavirus diseases (COVID-19) in China. Zhonghua Liu Xing Bing Xue Za Zhi 2020, 41, 145-151.

43. Lai, C.C.; Shih, T.P.; Ko, W.C.; Tang, H.J.; Hsueh, P.R. Severe acute respiratory syndrome coronavirus 2 (SARS-CoV-2) and corona virus disease-2019 (COVID-19): The epidemic and the challenges. Int. J. Antimicrob. Agents 2020, 105924. [CrossRef] 
44. Chinazzi, M.; Davis, J.T.; Ajelli, M.; Gioannini, C.; Litvinova, M.; Merler, S.; Y Piontti, A.P.; Mu, K.; Rossi, L.; Sun, K.; et al. The effect of travel restrictions on the spread of the 2019 novel coronavirus (COVID-19) outbreak. Science 2020. [CrossRef]

45. Kozinets, R.V. Netnography. In The International Encyclopedia of Digital Communication and Society; Wiley: Hoboken NJ, USA, 2015; pp. 1-8.

46. Hammersley, M. Ethnography. In The Blackwell Encyclopedia of Sociology; Blackwell Pub.: Malden, MA, USA, 2007.

47. Bartl, M.; Kannan, V.K.; Stockinger, H. A review and analysis of literature on netnography research. Int. J. Technol. Mark. 2016, 11, 165-196. [CrossRef]

48. Rageh, A.; Melewar, T.; Woodside, A. Using netnography research method to reveal the underlying dimensions of the customer/tourist experience. Qual. Mark. Res. Int. J. 2013, 16, 126-149. [CrossRef]

49. Sumiala, J.M.; Tikka, M. Broadcast yourself-Global news! A netnography of the "flotilla" news on YouTube. Commun. Cult. Crit. 2013, 6, 318-335. [CrossRef]

50. Wang, Y.S.; Lee, W.L.; Hsu, T.H. Using netnography for the study of role-playing in female online games. Internet Res. 2017. [CrossRef]

51. Laato, S.; Pietarinen, T.; Rauti, S.; Paloheimo, M.; Inaba, N.; Sutinen, E. A review of location-based games: Do they all support exercise, social interaction and cartographical training. In Proceedings of the 11th International Conference on Computer Supported Education (CSEDU), Heraklion, Greece, 2-4 May 2019.

52. Bowler, G.M., Jr. Netnography: A method specifically designed to study cultures and communities online. Qual. Rep. 2010, 15, 1270.

53. Kozinets, R.V. Netnography: Doing Ethnographic Research Online; Sage Publications: New York, NY, USA, 2010.

54. Wang, L.; Zhan, Y.; Li, Q.; Zeng, D.D.; Leischow, S.J.; Okamoto, J. An examination of electronic cigarette content on social media: analysis of e-cigarette flavor content on Reddit. Int. J. Environ. Res. Public Health 2015, 12, 14916-14935. [CrossRef]

55. Gioia, D.A.; Corley, K.G.; Hamilton, A.L. Seeking qualitative rigor in inductive research: Notes on the Gioia methodology. Organ. Res. Methods 2013, 16, 15-31. [CrossRef]

56. Google. COVID-19 Mobility Report. Available online: https://www.google.com/covid19/mobility (visited on 14 May 2020).

57. Apple. COVID-19 Mobility Report. Available online: Https://www.apple.com/covid19/mobility (visited on 14 May 2020).

58. Norman, D.A. Affordance, conventions, and design. Interactions 1999, 6, 38-43. [CrossRef]

59. Juhász, L.; Hochmair, H.H. Where to catch 'em all?-a geographic analysis of Pokémon Go locations. Geo-Spat. Inf. Sci. 2017, 20, 241-251. [CrossRef]

60. Niantic. Pokémon GO Updates. Available online: https://pokemongolive.com/en/post/ (accessed on 24 March 2020).

61. Niantic. Updates to Upcoming Ingress Events. Available online: https://community.ingress.com/en/ discussion/10024/updates-to-upcoming-ingress-events/p1?new=1 (accessed on 24 March 2020).

62. Niantic. Temporary in-Game Changes Made to INGRESS. Available online: https://community. ingress.com/en/discussion/10095/temporary-in-game-changes-made-to-ingress/p1?new=1 (accessed on 24 March 2020).

63. Ludia. Jurassic World Alive I Ludia Games and COVID-19. Available online: https://forum.ludia.com/t/ news-jurassic-world-alive-ludia-games-and-covid-19/124718 (accessed on 24 March 2020).

64. World Health Organization. Rational Use of Personal Protective Equipment for Coronavirus Disease (COVID-19): Interim Guidance, 27 February 2020; Technical Report; World Health Organization: Geneva, Switzerland; 2020.

65. Deterding, S.; Dixon, D.; Khaled, R.; Nacke, L. From game design elements to gamefulness: Defining "gamification". In Proceedings of the 15th International Academic MindTrek Conference: Envisioning Future Media Environments, Tampere Finland; Association for Computing Machinery. New York, NY, USA, 2011; pp. 9-15. [CrossRef]

66. Connolly, T.M.; Boyle, E.A.; MacArthur, E.; Hainey, T.; Boyle, J.M. A systematic literature review of empirical evidence on computer games and serious games. Comput. Educ. 2012, 59, 661-686. [CrossRef]

67. Laato, S.; Kordyaka, B.; Rauti, S.; Hyrynsalmi, S.M.; Hoikkala, M.; Pietarinen, T.; Laajala, T.D.; Paloheimo, M.; Inaba, N.; Hyrynsalmi, S. Do Primal Instincts Explain Engagement in Location-Based Games? In Proceedings of the 4th GamiFIN Conference, Levi, Finland, 1-3 April 2020. 
68. MMOWG.net. Wargaming-COVID-19 Virus-Bonus Code. Available online: https://www.mmowg.net/ wargaming-covid-19-virus-bonus-code/ (accessed on 5 April 2020).

69. Ubisfot. Play Your Part, Play At Home-Ubisoft Update. Available online: https:/ / news.ubisoft.com/en-us / article/3B6A1Hsg5fravgjxJykeEc/ play-your-part-play-at-home-ubisoft-update (accessed on 5 April 2020).

70. BusinessWire. Games Industry Unites to Promote World Health Organization Messages Against COVID-19; Launch \#PlayApartTogether Campaign. Available online: https://www.businesswire.com/news/ home/20200328005018/en/Games-Industry-Unites-Promote-World-Health-Organization (accessed on 5 April 2020).

71. Bartik, A.W.; Bertrand, M.; Cullen, Z.B.; Glaeser, E.L.; Luca, M.; Stanton, C.T. How Are Small Businesses Adjusting to COVID-19? Early Evidence from a Survey; Technical Report; National Bureau of Economic Research: Cambridge, MA, USA, 2020; doi:10.3386/w26989. [CrossRef]

72. Baldwin, R.; Tomiura, E. Thinking ahead about the trade impact of COVID-19. Econ. Time COVID-19 2020, $59,298220$.

73. Gough, C. Number of Video Gamers Worldwide in 2018, by Region. Available online: https://www.statista. com/statistics/293304/number-video-gamers/ (accessed on 5 April 2020).

74. Lwin, M.O.; Saw, S.M. Protecting children from myopia: A PMT perspective for improving health marketing communications. J. Health Commun. 2007, 12, 251-268. [CrossRef] [PubMed]

75. Duncan, L.A.; Schaller, M.; Park, J.H. Perceived vulnerability to disease: Development and validation of a 15-item self-report instrument. Personal. Individ. Differ. 2009, 47, 541-546. [CrossRef]

76. Lemmens, J.S.; Valkenburg, P.M.; Peter, J. Development and validation of a game addiction scale for adolescents. Media Psychol. 2009, 12,77-95. [CrossRef]

77. LaRose, R.; Lin, C.A.; Eastin, M.S. Unregulated Internet usage: Addiction, habit, or deficient self-regulation? Media Psychol. 2003, 5, 225-253. [CrossRef]

(C) 2020 by the authors. Licensee MDPI, Basel, Switzerland. This article is an open access article distributed under the terms and conditions of the Creative Commons Attribution (CC BY) license (http:/ / creativecommons.org/licenses/by/4.0/). 